\title{
Conduzindo um garanhão de forma segura para cobertura ou colheita de sêmen
}

Handling a breeding stallion to in-hand natural service or semen collection

\author{
Rodrigo Arruda de Oliveira ${ }^{1}$ \\ ${ }^{1}$ Laboratório de Reprodução Animal da Faculdade de Agronomia e Medicina Veterinária da Universidade de \\ Brasilia $(F A V / U n B)$ - Brasília, DF
}

\begin{abstract}
Resumo
Cavalos de alto valor genético, morfológico e funcional adquirem valorização comercial, tornando-se garanhões que, frequentemente ultrapassam valores superiores a milhões de reais. Várias pesquisas abordam diluentes para sêmen fresco e congelado, melhoria da qualidade seminal, infertilidade, mas pouco se pesquisa e publica a respeito da contenção e condução do garanhão para colheita de sêmen/cobertura. Embora, na maioria das vezes não seja o médico veterinário que conduz esses animais para a sala de colheita de sêmen, é importante ter conhecimento do manejo desses animais, já que acidentes, às vezes fatais, são relatados em diversos lugares do Brasil e do mundo. Portanto, objetivou-se com esta revisão abordar os principais métodos de contenção e condução de um garanhão para a área de cobertura ou colheita de sêmen no intuito de minimizar riscos e acidentes.
\end{abstract}

Palavras-chave: Cabrestos, contenção, equino, manequim, reprodutor.

\begin{abstract}
Few horses become stallions, due to that, they have high genetic merit and commercial value; Usually, more than millions of reais. Lots of research has been addressed to extenders for fresh and frozen semen, improvement of seminal quality, infertility; However, not that much has been researched and published about the restraint and handling a breeding stallion to in-hand natural service or semen collection. Although, most of the time it is not the veterinarian who handles these animals to the breeding environment. It is essential to know how to do in a safety way, since accidents, sometimes fatal, have been reported in different places in Brazil and the world. Therefore, this review aimed to address the restraint methods and handle a breeding stallion to a breeding-Shed room.
\end{abstract}

Keywords: Breeding dummy, equine, halter, restraint, sire.

\section{Introdução}

Apenas um número pequeno de cavalos se torna reprodutores, e por três razões: pedigree, desempenho e conformação. Os métodos de manejo aplicados na criação desses animais até o ponto de se tornarem reprodutores podem ter efeitos benéficos ou maléficos no comportamento desses garanhões (Varner, 2005). O manejo inadequado desses animais e a falta de contenção efetiva propiciam com certa frequência acidentes, às vezes fatais, envolvendo garanhões, éguas, veterinários e pessoas encarregadas em conduzir os animais no momento da cobertura ou colheita de sêmen.

Alguns criadores acreditam que as tendências agressivas dos garanhões não devem ser desencorajadas tão ativamente, já que seria o que os torna bons reprodutores. Porém, há uma distinção entre uma libido aumentada (que não deve ser desencorajada) e uma agressividade excessiva, que pode ser perigosa tanto para o condutor como para a égua. Não há nenhuma evidência que um garanhão "bemeducado" tenha taxas de concepções inferiores.

O macho reprodutor equino, geralmente, adota uma postura mais altiva, imponente e agressiva frente a uma égua em cio ou quando conduzido ao manequim artificial na sala de colheita de sêmen. Além de se prever o comportamento desse animal pela linguagem corporal, antecipando movimentos perigosos, o animal precisa ter uma contenção mínima, mas efetiva com um cabresto adequado. Entretanto, devido ao grande número de faculdades de medicina veterinária no Brasil e ao perfil mais urbano dos discentes do curso, poucos alunos e egressos tem vivência e conhecimento mais aprofundado

'Correspondência: rodrigoarruda $@$ unb.br Recebido: 12 de junho de 2020

Aceito: 25 de março de 2021 
do comportamento e da atitude dos cavalos, o que os auxiliaria a antecipar alguns movimentos dos garanhões, que embora considerados normais, são perigosos e até fatais (MacLeay, 2007).

De acordo com Gronqvist et al. (2016) a maioria dos acidentes com alunos do curso de medicina veterinária envolvem coices, mordidas ou pisões no pé e articulações. Como presas, os equinos têm um reflexo de fuga ou de luta muito exacerbado frente a situações que eles consideram como perigo (Gronqvist et al., 2016; McDonnell, 2016a). Para evitar e amenizar esses acidentes, além da adequada leitura da linguagem corporal do cavalo e a condução do garanhão com cabresto de qualidade e seguro é necessária, sendo o material publicado a respeito desse tema escasso. Portanto, objetivou-se com essa revisão abordar as maneiras de contenção e condução de um garanhão para a área de cobertura ou colheita de sêmen.

\section{Contenção}

Embora inadequado e não indicado, a maioria dos garanhões permanece em cocheiras, sem se exercitar e com alimentação rica em grãos a maior parte do dia. Isto pode gerar além de problemas metabólicos e digestivos, acúmulo de energia, resultando em um animal mais agressivo e de difícil controle com cabrestos de corda, geralmente utilizados nas propriedades do Brasil. É importante retirar os garanhões da cocheira em outros momentos, e não somente para colheita ou cobertura, para que possam se exercitar em piquete, andador ou redondel por pelo menos $3 \mathrm{~h}$ ao dia, ou serem montados/treinados (Araújo et al., 2015). Os garanhões deverão também aprender comandos como parar e recuar, para obedecer quando solicitado e recuem sem voltar a garupa para quem os conduz, garantindo maior segurança à colheita/monta (Varner, 2005).

Diversos métodos de contenção são utilizados para condução de garanhões para a colheita de sêmen/cobertura. A maioria com baixo controle do animal e de risco para o condutor, podendo o garanhão se soltar ou tomar o controle da situação, causando acidentes, às vezes fatais. $\mathrm{O}$ mercado oferece desde cabrestos mais simples consistindo em testeira e focinheira (Fig. 1A), que se muito folgados permitem que o animal se solte; o cabresto de 7 nós ou Rope halter (Fig. 1B) e o cabresto de náilon/polipropileno com cabo de corda (Buckle halter), geralmente muito curtos (Fig. 1C e Fig. 1D), que podem queimar a mão do condutor e obter baixo controle do animal em garanhões mais enérgicos ou mal manejados. Além do mais, se o condutor segurar na fivela do mosquetão quando maneja o animal, há o risco de abertura e fuga do garanhão.

Um dos métodos mais seguros e preconizados para a condução de garanhões é utilizado pelos criadores de cavalos de corrida, já que nenhuma biotécnica da reprodução é permitida e o reprodutor necessita saltar na égua para realizar a cobertura. Esse método é amplamente utilizado na condução de garanhões nos Estados Unidos (Fig. 1E). Outro cabresto tão eficiente, e muito utilizado na Europa, principalmente em países como Alemanha e Áustria, para manejo de cavalos de salto, adestramento, entre outros está representado na Figura 1F (Bridão Hanoverano).

O bridão Hanoverano (Hannoveranische Trense) consiste em uma cabeçada de couro com bridão leve, no qual são fixadas duas rédeas de couro longas. Acredita-se que esse sistema surgiu na Alemanha em haras estatal da Prússia há mais de 100 anos (Informação pessoal Dra. Christine Aurich, Vetmeduni Vienna). Para a colheita de sêmen, o garanhão deve ser guiado pelas longas rédeas, a rédea esquerda corre livremente para a mão esquerda do condutor, e a direita passa sobre a cernelha do reprodutor e então para a mão direita do guia (Fig. 2). O condutor deve se posicionar na altura da paleta esquerda do reprodutor para ficar fora da zona de perigo em caso de coices ou manotaços (Waberski e Sieme, 2009). Por segurança, as rédeas nunca devem ser enroladas na mão do condutor e nem ser arrastadas no chão.

Difundida pelo mundo, principalmente no meio do cavalo de corrida, de origem ainda incerta, consiste em cabresto de couro bem ajustado à cabeça do animal e um cabo de couro de aproximadamente 3,40m com uma corrente de $80 \mathrm{~cm}$ acoplada ao cabo (Varner, 2005, McDonnell, 2016b). É importante que o cabo do cabresto seja longo, para manter uma maior distância do garanhão caso seja necessário, respeitando o espaço individual do animal. Esse cabresto pode ser utilizado em vários cenários de contenção de acordo com a Fig. 3. Para que a corrente se mova de maneira adequada no cabresto, é importante que as argolas do cabresto sejam redondas e não quadradas. O recomendando é trabalhar sempre com a corrente no chanfro do reprodutor respeitando o bem-estar (Campbell e Sandøe, 2015), proporcionando pressão e alívio imediato quando o garanhão responde ao comando, e não movimentos bruscos (Varner, 2005) para evitar que a corrente lesione o chanfro ou boca do animal. Caso não ocorrer a ação necessária, pode-se intensificar a contenção com a corrente na boca. 


\section{ObD}

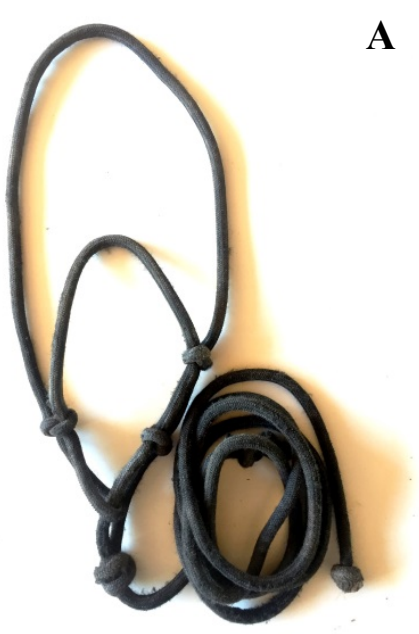

A
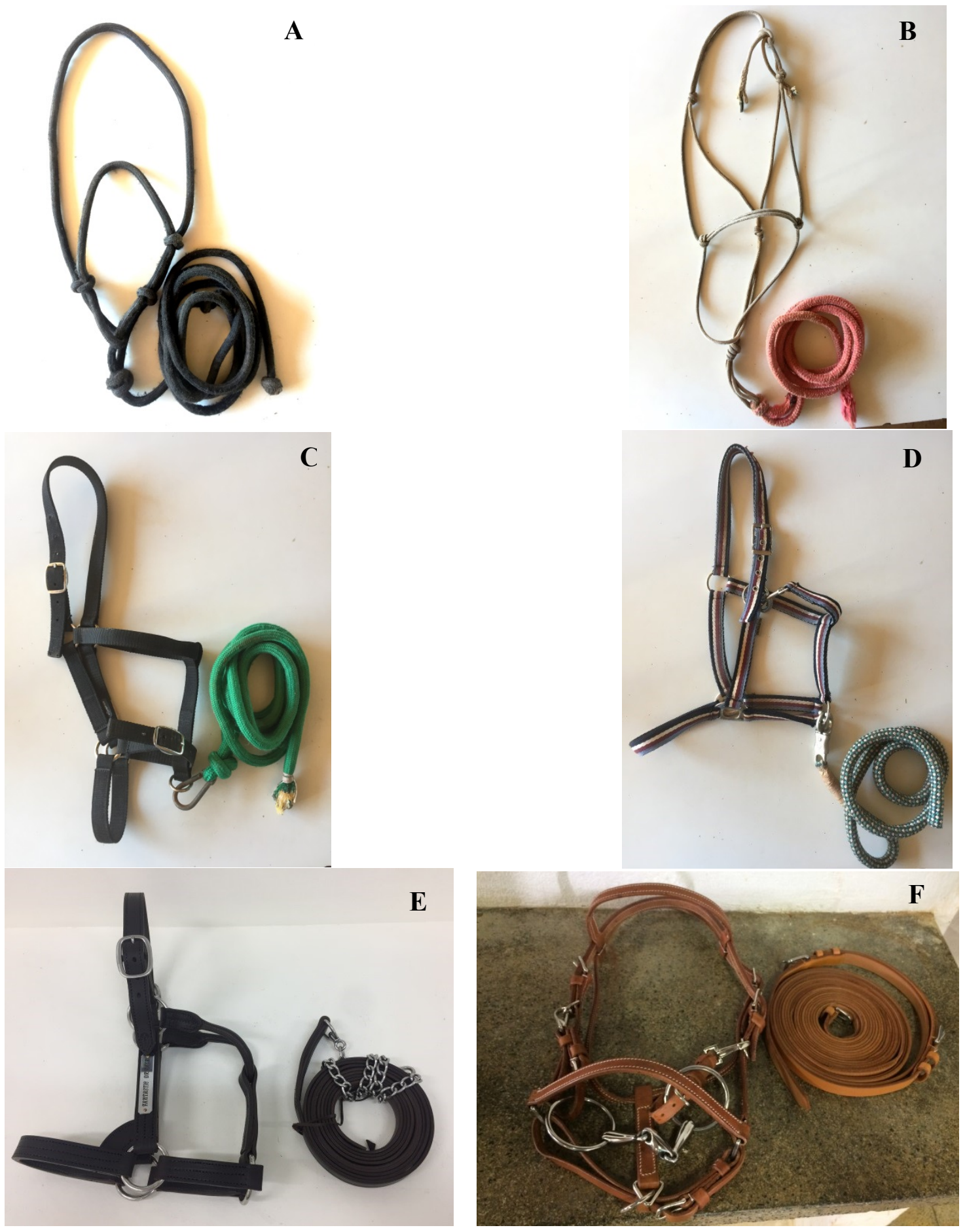

Figura 1. Métodos de contenção do garanhão. A) Cabresto simples com testeira e focinheira. B) Cabresto de 7 nós (Rope halter). C) Cabresto de náilon. D) Cabresto de polipropileno com cabo de mosquetão. E) Cabresto americano com corrente anexada ao cabo de couro. F) Bridão Hanoverano com embocadura e rédeas longas de couro. 

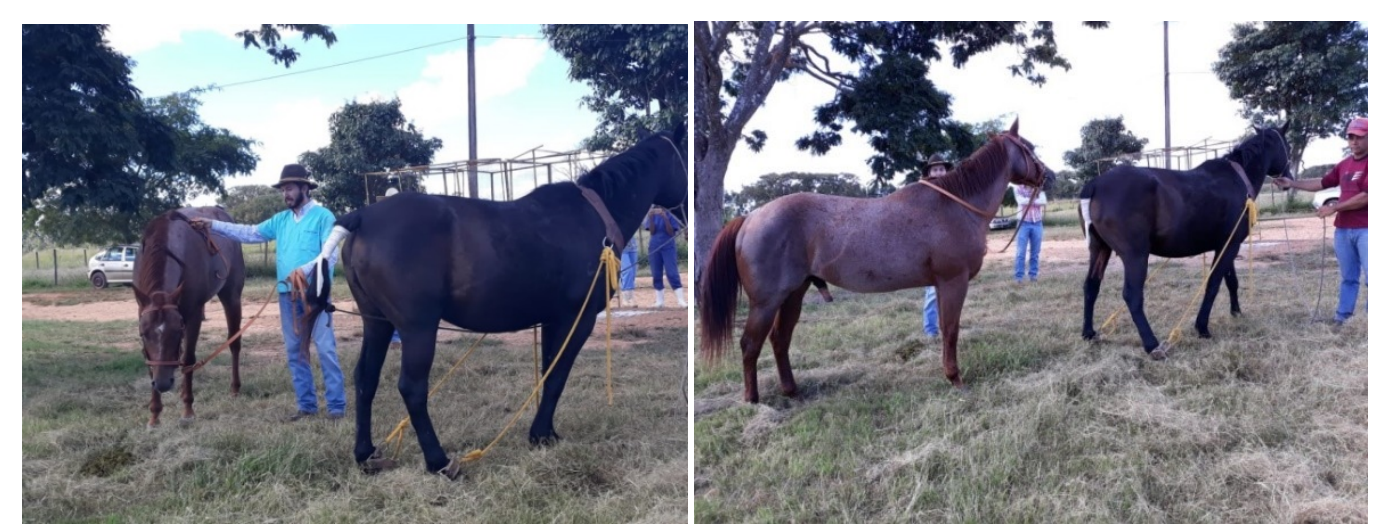

Figura 2. Utilização do Bridão Hanoverano. A) Rédea esquerda livremente na mão esquerda. B) Rédea direita pela cernelha, na mão direita.
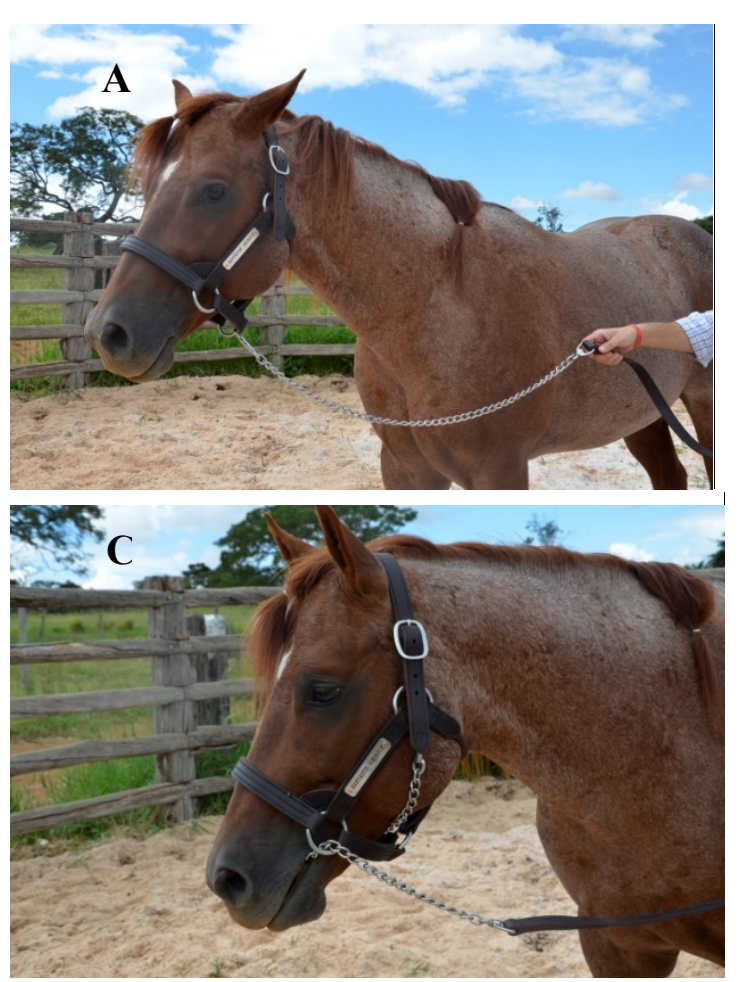

Figura 3. Algumas formas de utilização da corrente no cabresto, intensidade crescente de contenção. A) Corrente na argola da guia. B) Corrente sobre o chanfro. C) Corrente na boca. D) Corrente na gengiva.

Em casos excepcionalmente graves com relação a agressividade, a corrente poderia ser utilizada pressionando a gengiva (particularmente não recomendo, já que o condutor pode causar sérias lesões com pressões inadequadas). É importante lembrar que vários outros pontos devem ser analisados com relação à vida e ao manejo adequado desse animal fora de situações de monta, e corrigidos antes de se pensar em intensificar a contenção com a corrente na boca. É recomendando que o condutor segure no cabo do cabresto e não na corrente, para evitar lesão na mão do guia.

\section{Condução}

Considerando princípios básicos do "horsemanship", todos esses métodos de contenção devem ser aplicados com pressão, e alívio da pressão assim que o animal responder ao que foi solicitado. Dessa maneira, é importante evitar pressão quando o garanhão estiver respondendo de maneira adequada e não desencoraje hábitos normais do garanhão, como vocalização, arqueamento de pescoço e "striking" 
próximo à égua.

O condutor sempre deve guiar o garanhão na altura da cernelha do animal, sendo considerada uma região de maior segurança, evitando ser atingido por possíveis coices, manotaços, mordidas ou ser atropelado pelo reprodutor se estiver a frente do animal (Varner, 2005; Waberski e Sieme, 2009; McDonnell, 2016b).

É importante que todos os presentes na área de cobertura ou colheita de sêmen saibam exatamente qual o seu papel e os passos a serem dados, para evitar quaisquer acidentes. Equipe essa que deve ser treinada anteriormente, e não montada apenas no dia da colheita de sêmen. O número de pessoas, assim como o barulho na área de cobertura devem ser minimizados, a fim de não distrair o garanhão (McCartthy e Umphenour, 1992; Varner, 2005; McDonnell, 2016b).

Se o manequim artificial for utilizado para a colheita de sêmen, a distância para a égua em cio, deve ser maior para um garanhão de alta libido e menor para um garanhão de baixa libido, evitando o contato direto dos animais, por motivos higiênicos e de segurança (McDonnell, 2016a). Para a colheita, após a monta no manequim, é recomendado que o condutor se posicione próximo a cabeça do animal e que o veterinário também esteja do mesmo lado para realizar a colheita. Caso o garanhão não ejacule no primeiro salto e desça do manequim, o condutor irá puxar a cabeça do animal para o mesmo lado que ambos estão posicionados, colocando a garupa e os membros posteriores para o lado oposto, evitando assim, possíveis acidentes com coices. Já no método europeu, o condutor pode se posicionar do lado esquerdo e o veterinário do lado direito, pois no momento da descida, quem guia o garanhão, puxa a rédea direita e o cavalo vira a cabeça para o lado do coletador e a garupa para o lado oposto.

Se a colheita de sêmen for realizada com o uso de uma égua em cio ou se o objetivo for a monta controlada da égua, é recomendando que ela seja contida com peias e que tenha uma pessoa no cabresto da égua, evitando que ela se movimente. Neste primeiro contato, recomenda-se apresentar o focinho do garanhão ao focinho da égua a fim de mimetizar as condições naturais e melhorar a libido do garanhão (McCarthy e Umphenour, 1992; McDonnell, 2000).

Após apresentar a égua ao garanhão, ele tende a expor o pênis, nesta hora o garanhão deve ser afastado e seu pênis lavado com água e seco. Então o garanhão é reconduzido ao local de colheita no qual o médico veterinário já deve portar vagina artificial previamente preparada. É permitido então que o garanhão monte o manequim ou égua em cio devidamente contida. Após a ejaculação, recomenda-se que o epílogo seja respeitado deixando o garanhão desmontar por vontade própria, evitando que uma saída antecipada da glande ereta de dentro da vagina da égua possa succionar sêmen (McCarthy e Umphenour, 1992; Varner, 2005).

Um dos maiores problemas na área de colheita de sêmen/cobertura é o garanhão começar a circular o condutor para montar o manequim/égua expondo seus membros posteriores a quem irá colher o sêmen e à égua. Esse movimento deve ser evitado, sempre recuando o garanhão.

Muitos garanhões são utilizados em diferentes haras e estado do país na mesma estação de monta, e outros fazem estação de monta nos dois hemisférios, o que torna ainda mais importante a padronização de contenção e condução desses reprodutores da forma correta e segura para que possam cobrir de maneira eficiente.

Cada garanhão deve ser visto e tratado com um indivíduo diferente, com comportamento e preferências específicas como por exemplo: pelagens, turno do dia para cobertura, égua que melhor o estimula. Tais características podem ser levadas em conta para facilitar e maximizar os resultados dos procedimentos (melhora na eficiência e libido (McCarthy e Umphenour, 1992; Varner et al., 2010; McDonnell, 2016a).

\section{Considerações finais}

O mercado de garanhões no Brasil está em ampla ascensão e a experiência prática tem mostrado que é melhor adotar uma atitude de "melhor prevenir do que remediar" quando esses reprodutores são conduzidos para colheita de sêmen ou cobertura. Diversos condutores já se machucaram manejando reprodutores, que eram considerados bem manejados e confiáveis. Lembre-se que fora de um ambiente de reprodução, o garanhão é um cavalo como o de qualquer outra categoria, calmo, de boa índole que precisa ser respeitado e ter suas necessidades básicas atendidas, para expressar o seu máximo potencial reprodutivo.

\section{Referências}

Araújo JM, Amorim GBAG, Pivato I, Oliveira RA. Principais pontos abordados no exame 
andrológico do reprodutor equídeo a campo. Braz J Equine Med, v.59, p.4-13, 2015.

Campbell MLH, Sandøe P. Welfare in horse breeding. Vet Rec, v.176, p.436-440, 2015.

Gronqvist G, Rogers C, Gee E, Bolwell C, Gordon S. The challenges of using horses for practical teaching purposes in veterinary programmes. Animals, v.6, 69, doi:10.3390/ani6110069, 2016.

MacLeay JM. Large-animal handling at the Colorado State University College of Veterinary Medicine. $J$ Vet Med Educ, v.34, p.550-553, 2007.

McCarthy P, Umphenour N. Management of stallions on large breeding farms. Vet Clin North Am Equine Pract, v.8, p.219-235, 1992.

McDonnell SM. Reproductive behavior of stallions and mares: comparison of free-running and domestic in-hand breeding. Anim Reprod Sci, v.60, p.211-219, 2000.

McDonnell SM. Revisiting clinical stallion sexual behavior: Applying ethology in the breeding shed. $J$ Equine Vet Sci, v.43, p.18-22, 2016a.

McDonnell SM. Advances in diagnostics and therapeutic techniques in breeding behavior disorders in stallions. Vet Clin North Am Equine Pract, v.32, p.513-519, 2016b.

Varner DD. Handling the breeding stallion. In: ANNUAL CONVENTION OF THE AMERICAN ASSOCIATION OF EQUINE PRACTIONERS, 51, 2005. Lexington: Proceedings... p.498-505, 2005

Varner DD, Love CC, Blanchard TL. Hartman DL, Bliss SB, Hayden SS, Voge J, Carroll BS, Eslick MC, Macpherson ML. Breeding-management strategies and semen-handling techniques for stallions - Case scenarios. In: ANNUAL CONVENTION OF THE AMERICAN ASSOCIATION OF EQUINE PRACTIONERS, 59, 2010. Lexington: Proceedings... p.215-226, 2010

Waberski D, Sieme H. Andrologische und spermatologische Untersuchung (Zuchttauglichkeitsuntersuchung) beim Hengst. In: Aurich C (Ed). Reproduktionsmedizin beim Pferd. Parey in MVS Medizinverlage Stuttugart, Germany. Second edition, p.259, 2009. 